\title{
Isolation and Identification of different local isolates of Candida spp. By biochemical tests
}

\author{
Sahar Basil Muhammed*1, Zena wajeeh aljader $^{2}$ \\ ${ }^{1,2}$ Department of Biology, College of Education for pure Science, University of Mosul, Mosul, Iraq \\ E. Mail ${ }^{1 *}$ sah94bas687874@gmail.com ${ }^{2}$ dr.zena.algader@uomos.edu.iq
}

(Received April 25, 2021; Accepted June 08, 2021; Available online August 28, 2021)

DOI: 10.33899/edusj.2021.168644, (C) 2021, College of Education for Pure Science, University of Mosul.

This is an open access article under the CC BY 4.0 license (http://creativecommons.org/licenses/by/4.0/).

\begin{abstract}
Study included, 10 local isolates were obtained from 25 isolates of Candida spp. From patients infected with Candidiasis in hospitals of Mosul city. The phenotypic, microscopic diagnosis and biochemical tests found the isolates were identified as Candida sp. Local isolates were tested for resistance to 8 different antibiotics and 6 heavy metal salts. All isolates were resistant to most antibiotics with ratio $100 \%$, except for the antibiotic nystatin (Nys), where all isolates showed sensitivity in the ratio $100 \%$. also The isolates showed sensitivity to four of the heavy metals salts in different proportions, while they were resistant to zinc chloride $(\mathrm{ZnCl} 2)$ and lead acetate $\mathrm{Pb}(\mathrm{CH} 3 \mathrm{COO}) 2$ with ratio $100 \%$.
\end{abstract}

Keyword: Candida spp, Candidiasis, Biochemical Testes.)

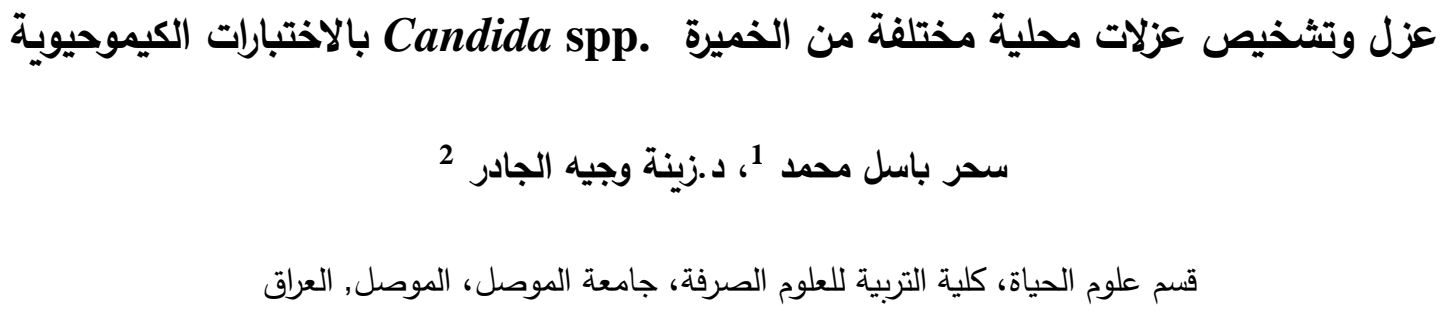

الخلاصة

تضمنت الدراسة الحصول على 10 عزلات محلية من بين 25 عزلة من الأشخيرة . Candida spp مناص المصابين بداء

المبيضات في مستشفيات مدينة الموصل ، شخصت العزلات باستخدام الصفات المظهرية والزرعية بالاضافة الى الاختبارات الكيموحيوية

، واظهرت نتائج الاختبارات انها تعود الى جنس الـ Candida ، اختبرت مقاومة العزلات المحلية لـ 8 انواع مختلفة من المضادات الحيوية

و6 أملاح من المعادن الثقيلة وكانت جميع العزلات مقاومة لأغلب المضادات الحيوية بنسبة 100\%، باستثناء المضاد الحيوي النستاتين

(Nys)

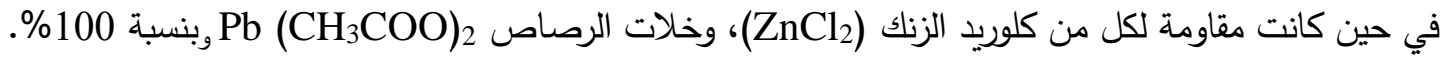




\section{Journal of Education and Science (ISSN 1812-125X), Vol: 30, No: 3, $2021(150-166)$}

Special Issue for Proceeding of $3^{\text {rd }}$ National (1 $1^{\text {st }}$ international conference of biology) (ICBSUM 2021) 5, 6 July

College of Education for Pure Science, University of Mosul, Mosul, Iraq.

الكلمات المفتاحية: .Candida spp ، داء المبيضات ،الاختبارات الكيموحيوية

\section{المقدمة: Introduction}

الخمائر هي فطريات وحيدة الخلية حقيقية النواة عديمة الحركة تكون خلاياها بيضوية الثكل او كروية وفي بعض الأحيان متطاولة

, Budding والانقسام الثنائي Binary fission [1 أما التكاثر الجنسي فيكون عن طريق تكوين جراثيم اسكية او بازيدية, تتميز مستعمراتها النامية على الوسط الغذائي بألوان مختلفة منها الأبيض، الكريمي، الأصفر ، الوردي، البرتقالي ونادراً ماتعطي ميسيليوم حقيقي او قد تثكل أحيانا مايعرف بالميسيليوم الكاذب [2] وهي من الناحية الاقتصادية تعد من أهم الكائنات الحية المستخدمة [3], تتواجد بصورة طبيعية وبصورة مرضية مثل خميرة الـ Candida والمعروفة بالمبيضات [4] يوجد حوالي (200) نوع عائد الى جنس إلا ان هنالك حوالي 20 نوعا فقط تكون مسؤولة عن داء المبيضات للإنسان والحيوان [5] وتعتبر إجبارية المعيشة وذلك لقلة وجودها حرة في الأوساط البيئية كالتربة والمياة [6]. تعتبر خميرة الـ Candida من الف الفطريات الإنتهازية والتي يمكن ان تسبب داء المبيضات (Candidiasis) الى ما يقارب من (30-50)\% من الافراد الاصحاء في العالم [7].

ينتمي جنس المبيضات الى الفطريات الناقصة ( Imperfect Fungi) ضمن شعبة Deuteromycotina صنف [8]، ولكن وجد أن بعض سلالات هذا النوع تكون سبورات كيسية لذلك صنفت تحت قسم الفطريات الكيسية Ascomycotina صنف Hemiascomyctes [9]. وان داء المبيضات والذي يطلق عليه Candidiasis [10] هو مصطلح واسع يشير الى التهاب الأعضاء الجلدية والمخاطية والداخلية التي تسببها الفطريات من جنس الـ Candida والتي يمكن ان تحدث في أي عمر وعادة ماتحدث في حالات ضعف المناعة المكتسبة عن الإصابة ببعض الامراض مثل مرض نقص المناعة المكتسبة. ويسبب داء المبيضات Candidiasis التهاب مجرى الدم والتهاب الأعضاء الداخلية داخل البطن و التهاب العظم, ويرتبط داء المبيضات إرتباطا وثيقا بالتقدم في التكنولوجيا الطبية ومعترف بـه على نطاق واسع كسبب رئيس للإصابة بالأمراض والوفيات في المراكز الصحية [11] [12]. تشكل داء المبيضات Candidiasis تهديدا للمرضى الراقدين في المستشفى و الذين يعانون من ضعف المناعة ، وتتفاقم مقاومة الادوية الناشئة بين أنواع المبيضات بسبب قلة توافر المضادات الفطرية والاثار الجانبية المرتبطة بها [13], إذ تتوفر حالياً ثلاثة أصناف من مضادات الفطريات والتي تتميزة بفعاليتها التثبيطية ضد أنواع خميرة . Candida spp وتثمل تلك المضادات على مجاميع Polyenes و Azole و Echinocadins [14], ويعد المضاد الفطري النستاتين Nystatin أول مضاد من مجموعة ال polyenes والذي تم اكتشافه عام 1950 واستخدم بنجاح في المراهم الجلدية السطحية Oral washes والغسولات الفوية Topical creams كعلاج لداء المبيضات [15]. وتعد ال Candida المسبب الثاني الأكثر شيوعا في الإصابة المهبلية Vaginal infection ويشار اليه أحيانا بالسلاق المهبلي Vaginal thrush فترة حياتهن من داء المبيضات المهبلي وتحدث الإصابة نتيجة للنمو المفرط لخميرة Candida albicans [16] ومن العوامل التي تساهم في زيادة الإصابة هي الحمل [17] وعدم التوازن الهرموني وتثبيط المناعة [18] او استخدام مضادات واسعة الطيف [19] .الهدف من البحث عزل أنواع مختلفة من خميرة الـ Candida وتشخيصها بالطرق المظهرية والمجهرية والزرعية والاختبارات الكيموحيوية . 
Journal of Education and Science (ISSN 1812-125X), Vol: 30, No: 3, 2021 (150-166)

Special Issue for Proceeding of $3^{\text {rd }}$ National (1 $1^{\text {st }}$ international conference of biology) (ICBSUM 2021) 5, 6 July

College of Education for Pure Science, University of Mosul, Mosul, Iraq.

\section{1. Meterials and Methods : المواد وطرائق العمل}

\section{Sample Collection : جمع العينات}

تم الحصول على العزلات الخميرية باخذ مسحات من الفم والإدرار والمهبل من المرضى المصابين بداء المبيضات في مستثفيات

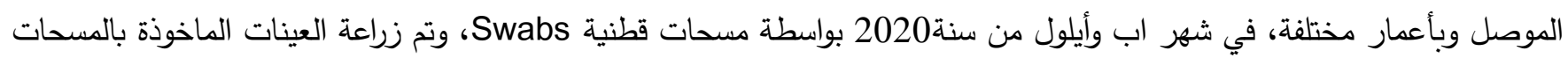
على الوسط الزرعي Sabouraud Dextrose agar (SDA وحضنت الاطباق بدرجة حرارة 37مْ لدة 48 ساعة ـ وقد تم اجراء البحث في مختبرات قسم علوم الحياة للدراسات العليا/كلية التربية للعلوم الصرفة / جامعة الموصل.

Isolation and Identification : العزل والتشخيص

زرعت العينات على الوسط Sabouraud Dextrose Agar المحضر من 4 غم دكستروز،1غم ببتون, 1.7 أكار , أذييت المكونات في 90 مل من الماء المقطر , وضبط ال pH عند 5.6 ثم عقم بجهاز المعقام, اذيب السكر في 10 مل من الماء المقطر

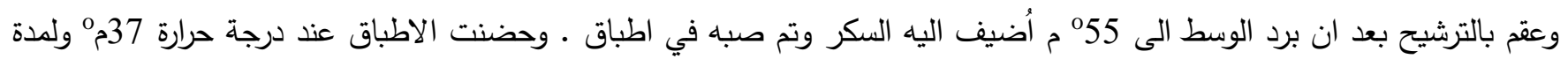

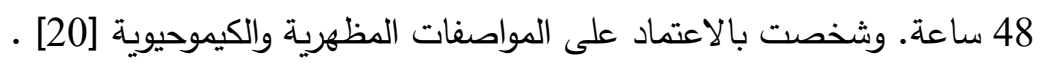

Biochemical Testes الاختبارات الكيموحيوية

1-اختبار تخمر السكريات Sugar Fermentation Test

تم تحضير وسط تخمر السكريات باذابة 4.5 غم من مستخلص الخميرة، 7.5 غم ببتون في 860 مل من الماء المقطر ـ اذيب 0.1 غم من صبغة المثيل الأحمر في 100 مل من الماء المقطر واخذ منه 40 مل واضيف الى باقي المكونات ، وصب الخليط في دوارق مخروطية بواقع 90 مل لكل دورق ثم عقدت بالمعقام. تم اذابة 2 غم من كل سكر في 10 مل من الماء المقطر واضيف الى الوسط بعد تعقيمه بالترشيح. صبت محتويات كل دورق في انابيب اختبار معقمة بواقع 10 مل لكل انبوبة. تم استخدام 8 أنواع مختلفة من السكر وهي (مالتوز، ، لاكتوز ، سكروز ، مانوز ، أرابينوز، كلاكتوز، كلوكوز ، زايلوز) تم نقل المستعمرات النامية بعمر 48 ساعة حضانة الى لى الانابيب الحاوية على وسط التخمر ووضعت في حاضنة هزازة بدرجة حرارة 28 مo لمدة 10-12 يوم مع ملاحظة العينات كل 24 ساعة

2-اختبار مقاومة وحساسية الخميرة المحلية للمضادات الحيوية وإملاح المعادن الثقيلة

\section{Sensitivity of local Yeast Isolates Candida spp for Antibiotic and Heavy Metals}

لمعرفة مدى مقاومة وحساسية العزلات للمضادات الحيوية واملاح المعادن الثقيلة تم استخدام وسط SDA بعد ان برد الوسط الى درجة

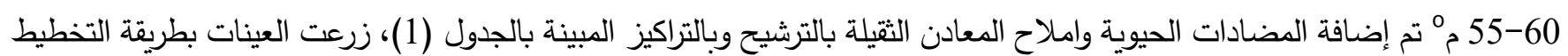
وحضنت لمدة 37 مُ وسجلت النتائج [22]. 
Journal of Education and Science (ISSN 1812-125X), Vol: 30, No: 3, $2021(150-166)$

Special Issue for Proceeding of $3^{\text {rd }}$ National (1 ${ }^{\text {st }}$ international conference of biology) (ICBSUM 2021) 5, 6 July College of Education for Pure Science, University of Mosul, Mosul, Iraq.

Candida spp جدول(1) المضادات الحيوية واملاح المعادن الثقيلة المستخدمة في دراسة حساسية عزلات خميرة

\begin{tabular}{|c|c|c|c|c|}
\hline المذيب & التركيز النهائي & المحلول الخزين & الرمز & المضادات الميوية \\
\hline كحول مطلق ايثانول & 100 & 5 & $\mathrm{Cm}$ & كلورامفينكول \\
\hline ايثانول 70\% & 100 & 20 & Ap & أمبيسلين \\
\hline كحول مطلق ايثانول & 100 & 10 & $\mathrm{Er}$ & الايرثرومايسين \\
\hline ايثانول 50\% & 100 & 10 & $\mathrm{Tc}$ & التتراسايكلين \\
\hline DMSO & 10000 & 100 & Flc & الفلوكونازول \\
\hline DMSO & 10000 & 100 & Ktc & ـالكيتوكونازول \\
\hline DMSO & 10000 & 100 & Itc & الايتراكونازول \\
\hline DMSO & 10000 & 100 & Nys & النستاتين \\
\hline ماء مقطر & 100 & 50 & $\mathrm{HgCl} 2$ & كلوريد الزئبق \\
\hline ماء مقطر & 100 & 50 & $\mathrm{CuSO} 4$ & كبريتات النحاس \\
\hline ماء مقطر & 100 & 50 & $\mathrm{CdCl} 2$ & كلوريد الكادميوم \\
\hline ماء مقطر & 100 & 100 & $\mathrm{CoCl} 2$ & كلوريد الكوبلت \\
\hline ماء مقطر & 100 & 50 & $\mathrm{ZnCl} 2$ & كلوريد الزنك \\
\hline ماء مقطر & 100 & 50 & $\mathrm{~Pb}(\mathrm{CH} 3 \mathrm{COO}) 2$ & خلات الرصاص \\
\hline
\end{tabular}

Catalase Test 3- 3تبار الكتاليز

اخذت المستعمرات النامية على وسط العزل (YPG) بعمر 48 ساعة وفرشت على شريحة زجاجية ثم اضيف اليها 1-2 قطرة من

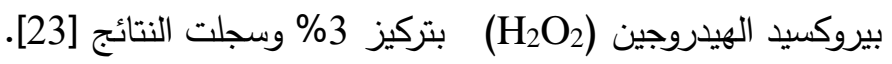




\section{Journal of Education and Science (ISSN 1812-125X), Vol: 30, No: 3, $2021(150-166)$}

Special Issue for Proceeding of $3^{\text {rd }}$ National (1 $1^{\text {st }}$ international conference of biology) (ICBSUM 2021) 5, 6 July

College of Education for Pure Science, University of Mosul, Mosul, Iraq.

\section{Starch Hydrolysis Test 4تخبار تحلل النثا}

تم تحضير الوسط باذابة 2.8 غم من الاكار المغذي (Nutrient Agar) و0.3 غم من النشا في 100 مل من الماء المقطر ثم عقم

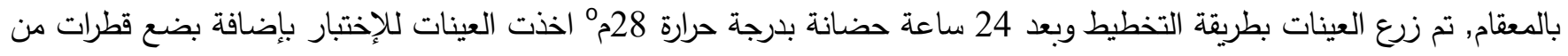
محلول الأيودين بدرجة حرارة المختبر .سجلت النتائج بعد مرور من 1-3 دقيقة من إضافة الأيودين [24].

\section{5elatin Liquefaction Test 5تبار الجيلاتين}

تم تحضير الوسط في 100 مل من الماء المقطر وذلك باذابة 12 غم جيلاتين (Gelatin)، 0.5 غم ببتون (pepton) و0.3 غم مستخلص لحم البقر (beef extract). عقم الوسط ثم صب في أنابيب إختبار ووضعت بشكل مائل لكي تتصلب، تم نقل المستعرات النامية الى انابيب الاختبار وحضنت لمدة 48 ساعة بدرجة 28م في حالة تحلل الوسط توضع الانابيب في الثلاجة بدرجة 4مْ لنصف ساعة بعدها سجلت النتائج[25].

6erm tube Formation Test اختبار تكوين ألانبوب الجرثومي اخذ جزء من المستعمرة ووضعها في انبوب اختبار معقم يحتوي على 0.5 مل من مصل دم الانسان وحضنت بدرجة 37مْ لددة [26] ساعات [26

\section{7-اختبار تكوين الابواغ الكلاميدية Chlamydospores Production Test}

تم تحضير الوسط باذابة 17 غم من Corn meal Agar ثم لقح الوسط بمستعمرات من خميرة المبيضات وحضنت في 30م

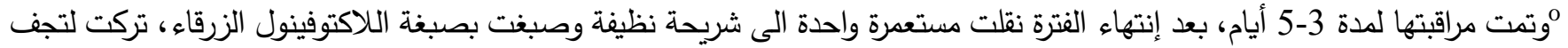
ووضع غطاء الشريحة عليها ثم فحصت تحت المجهر لرؤية السبورات الكلاميدية [27].

8rowth Test on Chrom Agar اختبار النمو على وسط كروم اكار أجري هذا الاختبار باخذ جزء من مستعمرة الخميرة النامية على وسط SDA بعر 24 ساعة وزرعت على وسط اكار الكروم حسب تعليمات الثركة المجزة وحضنت لمدة 24-48 ساعة بدرجة حرارة 37 م [28]. 9- اختبار تاثير اختلاف درجات الحرارة على النمو

\section{Test the Effect of Temperature Differences on Growth}

تم في هذا الاختبار استخدام وسط (SDA) حيث اخذت العينات وزرعت بطريقة التخطيط على الوسط وحضنت بدرجات حرارية مختلفة هي 28،37،45،23 م "لددة 48 ساعة وبعدها سجلت النتائج [46]. 
Journal of Education and Science (ISSN 1812-125X), Vol: 30, No: 3, $2021(150-166)$

Special Issue for Proceeding of $3^{\text {rd }}$ National (1 $1^{\text {st }}$ international conference of biology) (ICBSUM 2021) 5, 6 July College of Education for Pure Science, University of Mosul, Mosul, Iraq.

Results and discussion : النتائج والمناقشة

تشخيص العزلات المحلية Diagnosis of Local Isolates

تم الحصول على 10 عزلات محلية من خميرة الـ Candida والتي تم عزلها من أجزاء مختلفة من جسم الانسان الفم والمهيل والإدرار وشخصت بشكل مبدئي بالإعتماد على الثكل الخارجي Morphology للمستعمرات والصفات المجهرية, فظهرت المستعمرات بالوان متباينة ما بين الأبيض والكريدي ذات حواف ملساء واسطح ناعمة لماعة شكل (1) .تتفق هذه النتيجة مع [29] و[30] من حيث الصفات المظهرية للمستعمرات.

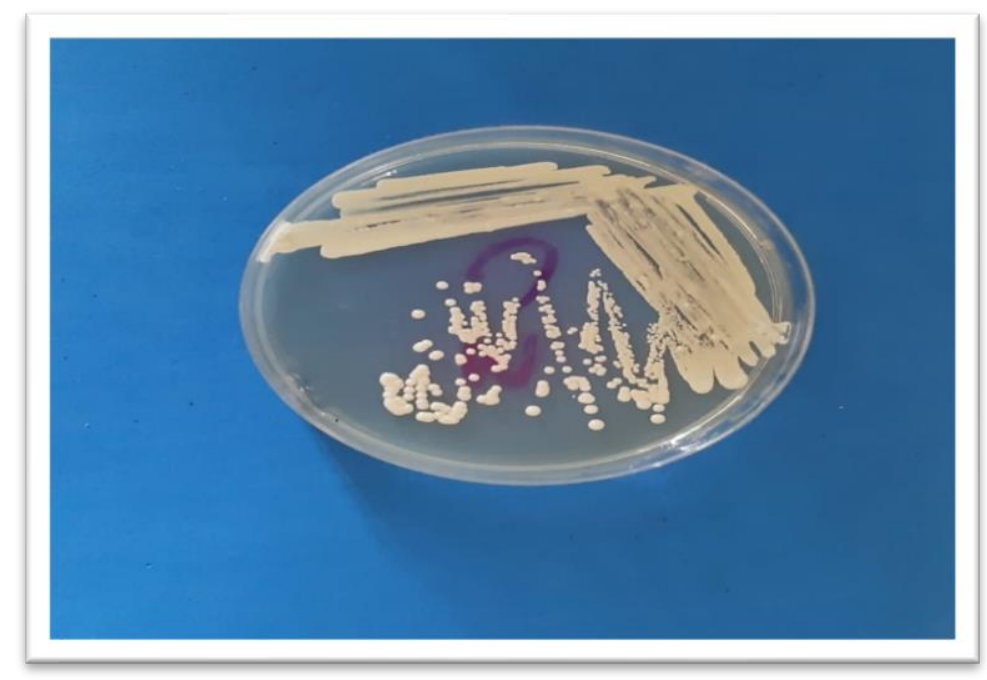

شكل (1) المظهر الخارجي للمستعرات المفردة من جس الـ Candida spp

Microscopic Test الفحص المجهري

ظهرت المستعمرات تحت المجهر كروية الثكل الى بيضاوية وكانت مفردة او متبرعمة مع وجود خيوط فطرية كاذبة Pseudohyphae أحيانا ،إضافة الى كونها موجبة لصبغة كرام شكل (2). وهذا يتفق مع [31] من حيث شكل الخلايا. 

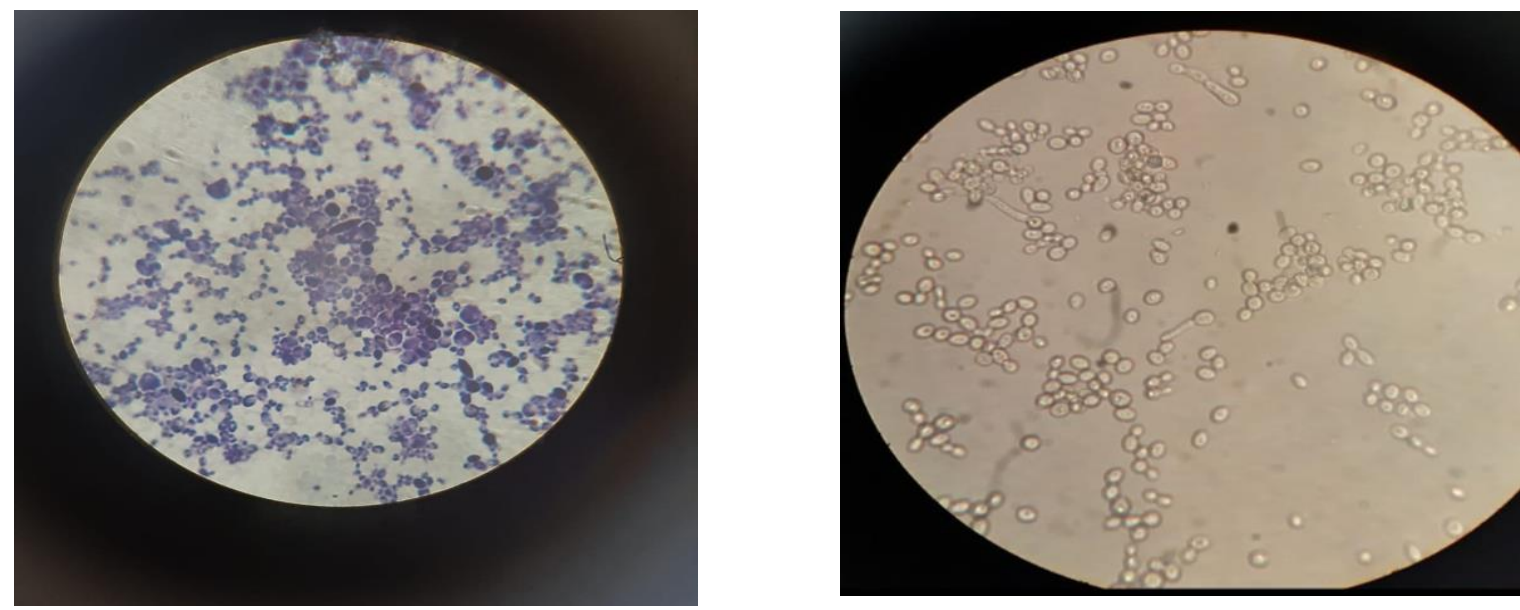

(أ) خلايا عزلات Candida spp) تحت المجر الضوئي بقوة تكبير (X100)

(ب) (Xلايا عزلات Candida spp) مصبوغة بصبغة كرام بقوة تكبير (X100)

Candida spp. الاختبارات الكيموحيوية لعزلات خميرة الـ

\section{Biochemical Test for isolates yeast Candida spp.}

بعد الحصول على عزلات خميرة الـ Candida spp وتثخيصها من حيث الفحص المجهري والثكل الخارجي للمستعرات. تم اجراء الاختبارات الكيموحيوية وكالاتي :

1- اختبار تخمر السكريات Sugars Fermentation Tests

بينت النتائج ان جميع العزلات كانت قادرة على تخمير السكريات (كلوكوز ،سكروز ، مالتوز ، مانوز ، كالاكتوز) وبنسبة 100\% حيث تغير لون الوسط من اللون الأحمر الى اللون الأصفر دلالة على تخمير السكر في حين لم تتمكن جميع العزلات من تخمير السكريات (لاكتوز) وبنسبة 100\%. شكل (3). ان عدم قدرة العزلات على تخمير سكر اللاكتوز يعود لعدم قدرتها على انتاج انزيخ _ والذي يعمل على تكسير اللاكتوز الى كلوكوز وكالاكتوز لتتمكن الخميرة من استهلاكه كمدر كاربوني [32] اما سكر الزايلوز فكانت العزلات (C1,C2,C3,C5,C9) غير قادرة على تخمير السكر ،جدول (2). هذه النتائج تتقق مع [33] و[34].من حيث قدرة الخميرة على تخمر السكريات وعدم قدرتها على تخمر سكر اللاكتوز • 
Journal of Education and Science (ISSN 1812-125X), Vol: 30, No: 3, 2021 (150-166)

Special Issue for Proceeding of $3^{\text {rd }}$ National (1 $1^{\text {st }}$ international conference of biology) (ICBSUM 2021) 5, 6 July College of Education for Pure Science, University of Mosul, Mosul, Iraq.

جدول(2) قدرة عزلات خميرة الـ .Candida spp على تخمير أنواع مختلفة من السكريات.

\begin{tabular}{|c|c|c|c|c|c|c|c|}
\hline زايلوز & كلوكوز & كلاكتوز & مانوز & سكروز & لاكتوز & مالتوز & العينات \\
\hline- & + & + & + & + & - & + & $\mathrm{C} 1$ \\
\hline- & + & + & + & + & - & + & $\mathrm{C} 2$ \\
\hline- & + & + & + & + & - & + & $\mathrm{C} 3$ \\
\hline+ & + & + & + & + & - & + & $\mathrm{C} 4$ \\
\hline- & + & + & + & + & - & + & C5 \\
\hline+ & + & + & + & + & - & + & C6 \\
\hline+ & + & + & + & + & - & + & C7 \\
\hline+ & + & + & + & + & - & + & C8 \\
\hline- & + & + & + & + & - & + & C9 \\
\hline+ & + & + & + & + & - & + & C10 \\
\hline
\end{tabular}

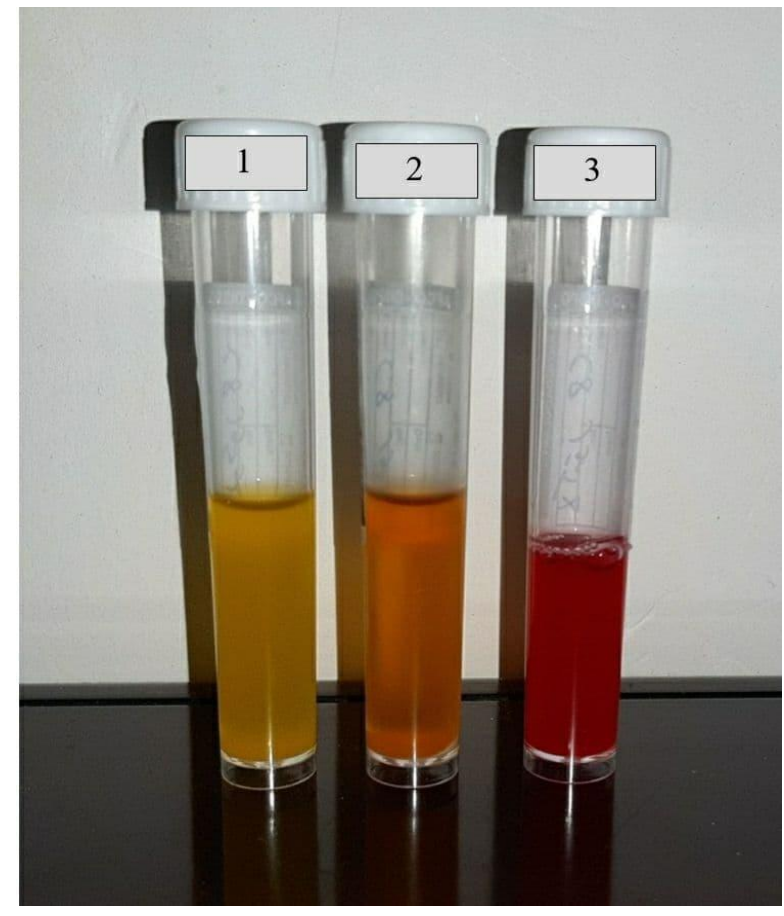

شكل(3) اختبار تخمر السكريات لعزلات الـ Candida spp

$$
\text { 1-سكر الكلوكوز 2-سكر المانوز }
$$


2-اختبار مقاومة وحساسية عزلات خميرة Candida spp للمضادات الحيوية واملاح المعادن الثقيلة

\section{Sensitivity of local Yeast isolates Candida spp for Antibiotic and Heavy metals}

بينت النتائج تباين العزلات المحلية للخميرة في مدى مقاومتها للمضادات الحيوية فقد أظهرت العزلات مقاومتها لكل من الامبسلين (Am)، كلورامفينيكول (Cm)، تتراسايكلين (Tc)، الايرثرومايسين (Er)، الفلوكونازول (Flu)، الكيتوكونازول (Keto)، الايتراكونازول

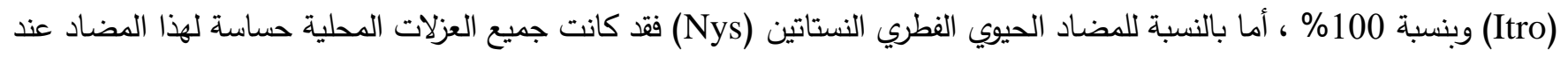
التركيز النهائي 1000 ميكروغرام/مل وبنسبة 100\% جدول (3). تعود قدرة النستاتين لقتل الجراثيم او تثبيط نموها الى تفاعله مع الاغشية

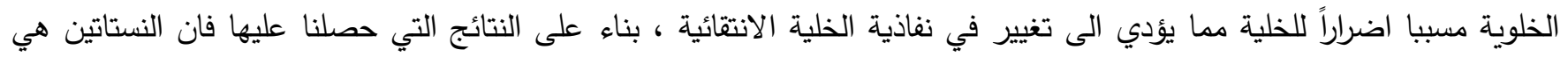

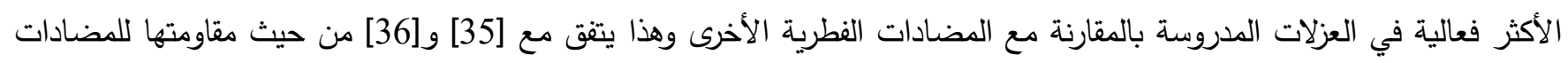

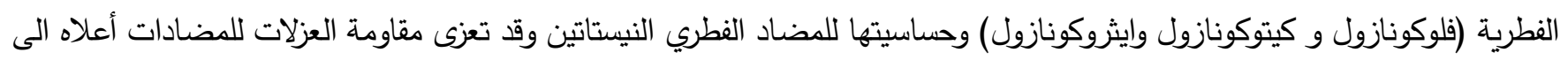

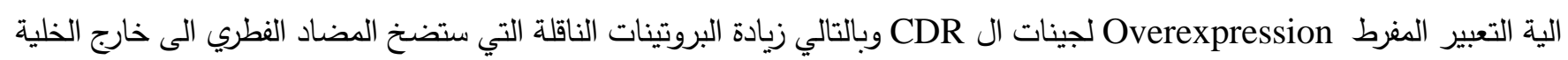

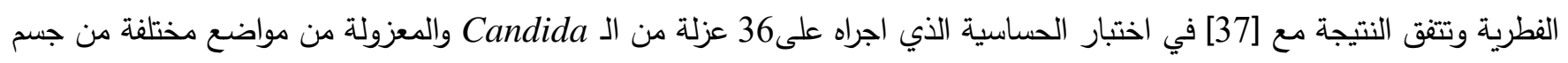
الانسان تجاه المضادات الفلوكونازول, الكيتوكونازول, الايتروكونازول والكلوتريمازول.

يتضح من الجدول (3) ان جميع العزلات المحلية لخميرة Candida spp كانت مقاومة لكل من كلوريد الزنك(CHCl (ZnC)، وخلات

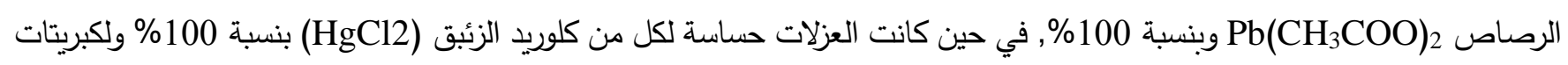
النحاس (CuSO

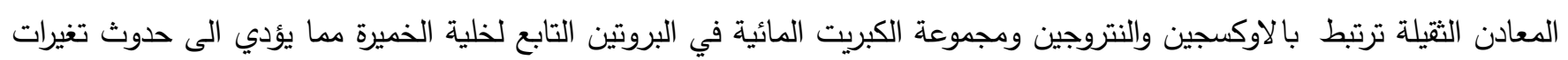

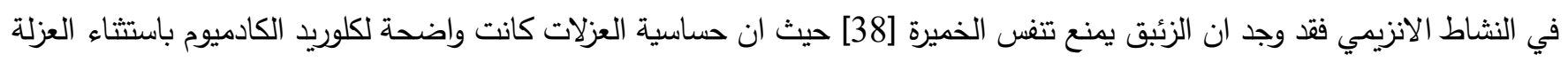

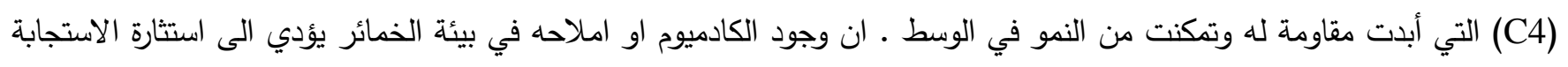

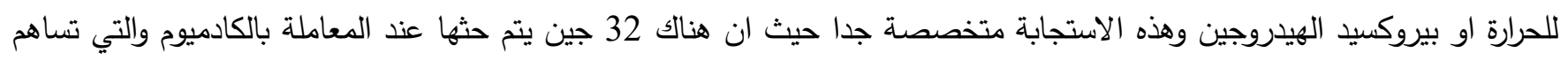

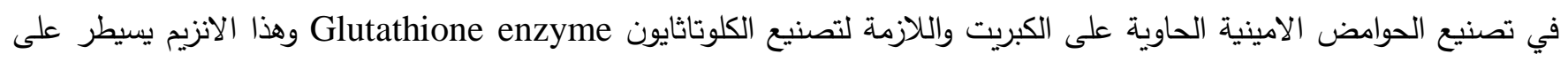
تركيز العناصر بعملية الاقتناص او الاحتجاز [39]. 
Journal of Education and Science (ISSN 1812-125X), Vol: 30, No: 3, $2021(150-166)$

Special Issue for Proceeding of $3^{\text {rd }}$ National (1 $1^{\text {st }}$ international conference of biology) (ICBSUM 2021) 5, 6 July College of Education for Pure Science, University of Mosul, Mosul, Iraq.

جدول3.إختبار الحساسية للمضادات الحيوية وأملاح المعادن لعدد من عزلات خميرة Candida Spp

\begin{tabular}{|c|c|c|c|c|c|c|c|c|c|c|c|c|}
\hline \multicolumn{10}{|c|}{ عزلات الخميرة قيد الاراسـة } & \multirow{2}{*}{$\begin{array}{l}\text { التركيز النهائي } \\
\text { UG/ML }\end{array}$} & \multirow[t]{2}{*}{ 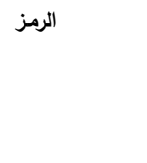 } & \multirow{2}{*}{ 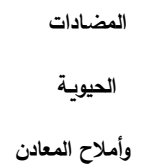 } \\
\hline $\mathrm{C} 10$ & $\mathrm{C} 9$ & $\mathrm{C} 8$ & $\mathrm{C} 7$ & $\mathrm{C} 6$ & $\mathrm{C} 5$ & $\mathrm{C} 4$ & $\mathrm{C} 3$ & $\mathrm{C} 2$ & $\mathrm{C} 1$ & & & \\
\hline $\mathrm{R}$ & $\mathrm{R}$ & $\mathrm{R}$ & $\mathrm{R}$ & $\mathrm{R}$ & $\mathrm{R}$ & $\mathrm{R}$ & $\mathrm{R}$ & $\mathrm{R}$ & $\mathrm{R}$ & 100 & $\mathrm{Cm}$ & كلورامفينكول \\
\hline $\mathrm{R}$ & $\mathrm{R}$ & $\mathrm{R}$ & $\mathrm{R}$ & $\mathrm{R}$ & $\mathrm{R}$ & $\mathrm{R}$ & $\mathrm{R}$ & $\mathrm{R}$ & $\mathrm{R}$ & 100 & AP & امبسلين \\
\hline $\mathrm{R}$ & $\mathrm{R}$ & $\mathrm{R}$ & $\mathrm{R}$ & $\mathrm{R}$ & $\mathrm{R}$ & $\mathrm{R}$ & $\mathrm{R}$ & $\mathrm{R}$ & $\mathrm{R}$ & 100 & $\mathrm{Er}$ & ايرثرومايسين \\
\hline $\mathrm{R}$ & $\mathrm{R}$ & $\mathrm{R}$ & $\mathrm{R}$ & $\mathrm{R}$ & $\mathrm{R}$ & $\mathrm{R}$ & $\mathrm{R}$ & $\mathrm{R}$ & $\mathrm{R}$ & 100 & $\mathrm{Tc}$ & تتراسايكلين \\
\hline $\mathrm{R}$ & $\mathrm{R}$ & $\mathrm{R}$ & $\mathrm{R}$ & $\mathrm{R}$ & $\mathrm{R}$ & $\mathrm{R}$ & $\mathrm{R}$ & $\mathrm{R}$ & $\mathrm{R}$ & 100 & Flu & فلوكونازول \\
\hline $\mathrm{R}$ & $\mathrm{R}$ & $\mathrm{R}$ & $\mathrm{R}$ & $\mathrm{R}$ & $\mathrm{R}$ & $\mathrm{R}$ & $\mathrm{R}$ & $\mathrm{R}$ & $\mathrm{R}$ & 10000 & Ktc & كيتوكونازول \\
\hline $\mathrm{R}$ & $\mathrm{R}$ & $\mathrm{R}$ & $\mathrm{R}$ & $\mathrm{R}$ & $\mathrm{R}$ & $\mathrm{R}$ & $\mathrm{R}$ & $\mathrm{R}$ & $\mathrm{R}$ & 10000 & Itc & ايتراكونازول \\
\hline $\mathrm{S}$ & $\mathrm{S}$ & $\mathrm{S}$ & $\mathrm{S}$ & $\mathrm{S}$ & $\mathrm{S}$ & $\mathrm{S}$ & $\mathrm{S}$ & $\mathrm{S}$ & $\mathrm{S}$ & 10000 & Nys & النستاتين \\
\hline $\mathrm{S}$ & $\mathrm{S}$ & $\mathrm{S}$ & $\mathrm{S}$ & $\mathrm{S}$ & $\mathrm{S}$ & $\mathrm{S}$ & $\mathrm{S}$ & $\mathrm{S}$ & $\mathrm{S}$ & 10000 & $\mathrm{HgCl}_{2}$ & كلوريد الزئيق \\
\hline $\mathrm{R}$ & S & S & $\mathrm{S}$ & $\mathrm{R}$ & S & $\mathrm{S}$ & $\mathrm{s}$ & S & $\mathrm{R}$ & 100 & $\mathrm{CuSO}_{4}$ & كبريتات النحاس \\
\hline $\mathrm{S}$ & $\mathrm{S}$ & $\mathrm{R}$ & $\mathrm{R}$ & $\mathrm{S}$ & $\mathrm{R}$ & $\mathrm{S}$ & $\mathrm{S}$ & $\mathrm{S}$ & $\mathrm{S}$ & 100 & $\mathrm{CdCl}_{2}$ & كلوريد الكادميوم \\
\hline $\mathrm{S}$ & $\mathrm{R}$ & $\mathrm{R}$ & $\mathrm{R}$ & $\mathrm{R}$ & $\mathrm{s}$ & $\mathrm{S}$ & $\mathrm{S}$ & $\mathrm{R}$ & $\mathrm{R}$ & 100 & $\mathrm{CoCl} 2$ & كلوربد الكوبلت \\
\hline $\mathrm{R}$ & $\mathrm{R}$ & $\mathrm{R}$ & $\mathrm{R}$ & $\mathrm{R}$ & $\mathrm{R}$ & $\mathrm{R}$ & $\mathrm{R}$ & $\mathrm{R}$ & $\mathrm{R}$ & 100 & $\mathrm{ZnCl} 2$ & كلوريد الزنك \\
\hline $\mathrm{R}$ & $\mathrm{R}$ & $\mathrm{R}$ & $\mathrm{R}$ & $\mathrm{R}$ & $\mathrm{R}$ & $\mathrm{R}$ & $\mathrm{R}$ & $\mathrm{R}$ & $\mathrm{R}$ & 100 & $\begin{array}{c}\mathrm{Pb}(\mathrm{CH} 3 \mathrm{COO}) \\
2\end{array}$ & خلات الرصاص \\
\hline
\end{tabular}

Catalase Test 3

بينت نتائج الاختبار قدرة جميع العزلات على انتاج انزيم الكتاليز وبنسبة 100\% .يستدل على النتيجة الموجبة بظهور فقاعات غازية بسبب تحلل البيروكسيد الى غاز الاوكسجين وماء وتتفق هذه النتائج مع [40] بعد اختبار 90 عزلة تعود لانواع مختلفة من جنس الـ Candida 58 عزلة منها كانت موجبة لإختبار الكتاليز .

Starch Hydrolysis Test اختبار تحلل النشا

أظهرت النتائج قدرة العزلات على تكوين مركبات الاميلود التي تتمكن من تحليل النشا والذي يكثف عن قدرة الاحياء المجهرية على تحليل النشا باستخدام الايودين حيث يغمر سطح المستعمرات بكمية مناسبة منه، وان ظهور الهالة الثفافة حول المستعمرة النامية تدل على تحلل النشا مما يؤكد افرازها لانزيم الاميليز،. وان قدرة الCandida على تحليل النشا يعود الى ان النشا مادة كاربوهيدراتية عبارة عن نوعين من الوحدات الأولى هي اميلوز Amylose والتي تكون بشكل سلاسل مستقيمة من الكلوكوز والثانية هي اميلوبكتين 
ذات السلاسل المتفرعة من الكلوكوز ولكي تتمكن الخميرة بصورة خاصة والاحياء المجهرية بصورة عامة من تحليل النشا فلا بد لها ان تكون قادرة على افراز انزيم الفا وبيتا اميليز لكسر سلاسل الاميلوز المستقيمة وكذلك يجب ان تكون قادرة على افراز انزيم 6lucosidase

\section{5elatin Liquefaction Test اختبار تحلل الجيلاتين-5}

Gelatinase enzyme بينت نتائج هذا الاختبار قدرة العزلات على تحلل الجيلاتين، وذلك لقدرتها على انتاج انزيم الجيلاتينيز الذي يعمل على تحليل بروتين الجيلاتين المكون الأساسي للوسط. هذه النتائج تتقق مع[42] عندما اختبر 172 عينة تمكنت من تحلل الجيلاتين بإستثناء 6 منها كانت غير قادرة على تحليله.

\section{6erm tube formation Test اختبار تكوين الانبوب الجرثومي}

أظهرت نتائج الثكل (4) بان معظم العزلات المحلية لم تتمكن من تكوين الانبوب الجرثومي بعد وضعها في انبوبة حاوية على

مصل الدم لمدة 2-2 ساعات باستثناء العزلات (C6 و C8) حيث ظهرت قابليتها على تكوين الانبوب الجرثومي والذي يعد صفة تثخيصية

للنوع albicans وهذه النتيجة جاءت مطابقة لنتائج [43] الذي ذكر ان C. albicans لها القدرة على تكوين انبوب الإنبات .

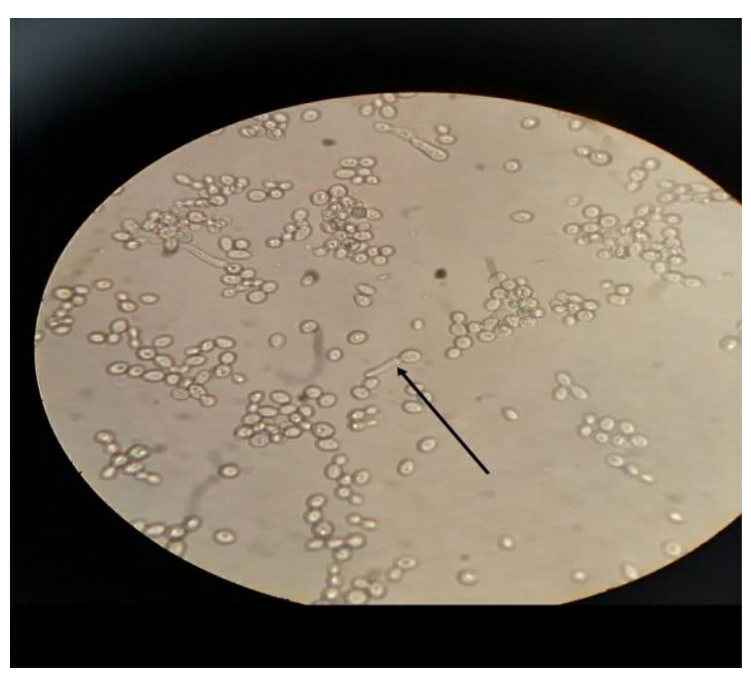

شكل 4- تكوين الانبوب الجرثومي Germ tube لبعض انواع الـ Candida 


\section{6hlamydospore formation Test اختبار تكوين السبورات الكلاميدية}

اوضحت نتائج الثكل (5) عدم قدرة العزلات المحلية على تكوين السبورات الكلاميدية عند تنميتها على وسط Corm meal Agar لمدة

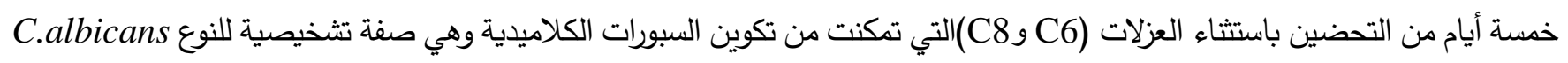
،وهذه النتيجة تتطابق مع [44] من حيث قدرة الخميرة C.albicans على تكوين السبورات الكلاميدية وتستعمل هذه الميزة لتحديد وتمييز • C.albicans

شكل( 5) تكوين السبورات الكلاميدية Chlamydospore لبعض أنواع الـ Candida

7rowth test on Chrom Agar اختبار النمو على وسط الكروم اكار

تم تشخيص أنواع المبيضات Candida spp المعزولة على الوسط التثريقي Chrom Agar حيث ظهرت بالوان مختلفة وكل لون

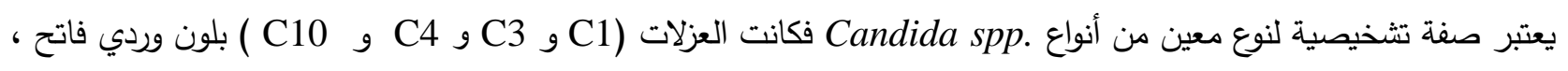

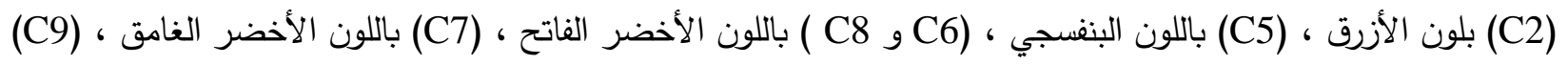

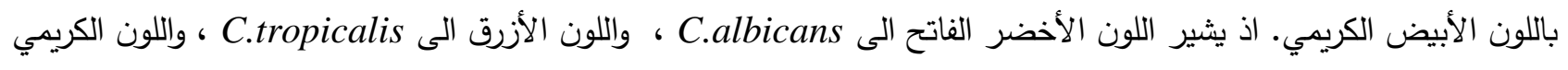
الى ل.Parapsilosihs ، واللون الوردي الفاتح الى C.krusei، واللون البنفجي الى C.glabrata واللون الأخضر الغامق الى C.dubliniensis حسب تعليمات الشركة المجزة للوسط شكل (6). تتفق هذه النتائج مع ماتوصلا اليهـ[45]. 

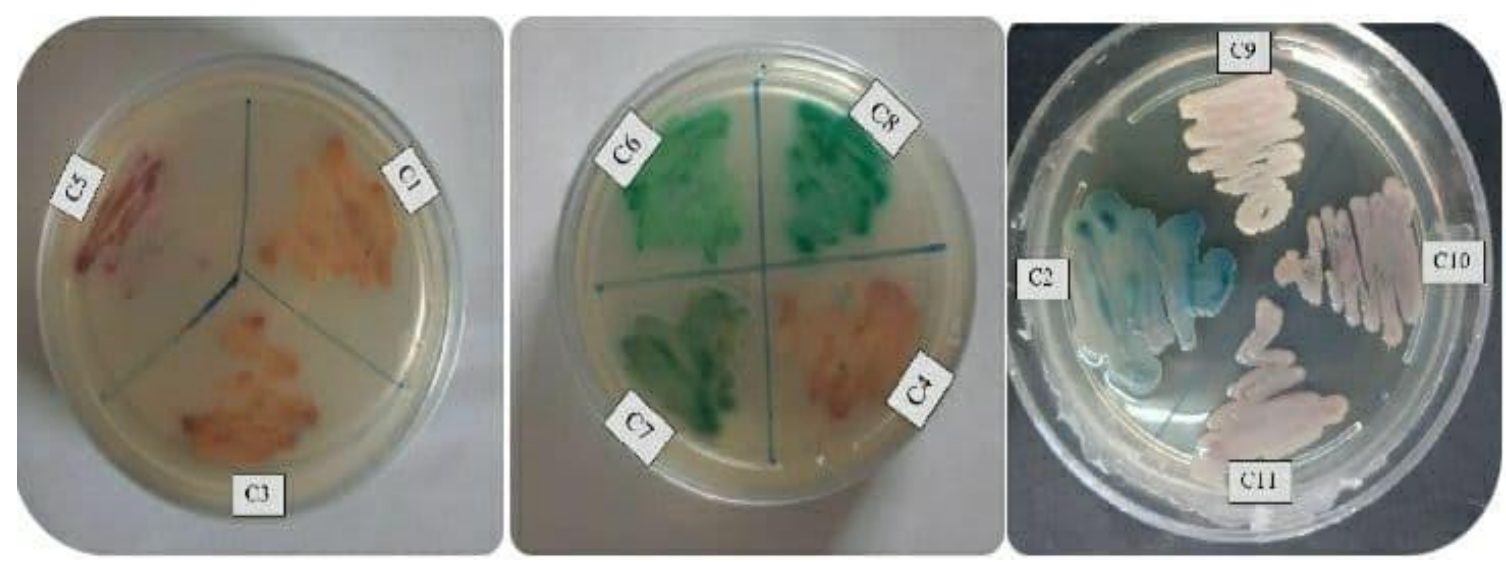

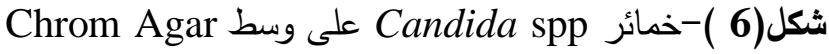

8- اختبار تاثير اختلاف درجات الحرارة على النمو

\section{The effect of temperature differences on growth Test}

تشير النتائج الى قدرة العزلات على النمو في مدى واسع من درجات الحرارة حيث أبدت العزلات نمواً ضعيفا عند درجة 23 مْ مأه

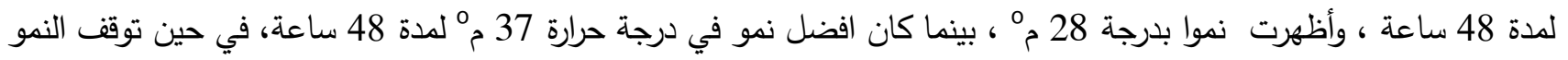

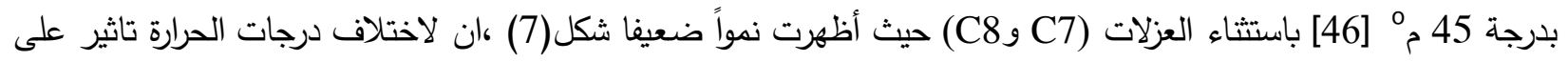
معدل النمو للخميرة فتأثيرها اما مثبط او محفز او قاتل ، ففي الدرجات الحرارة المنخفضة والتي تتراوح (0-10) م ${ }^{\circ}$ التبى انزيمات

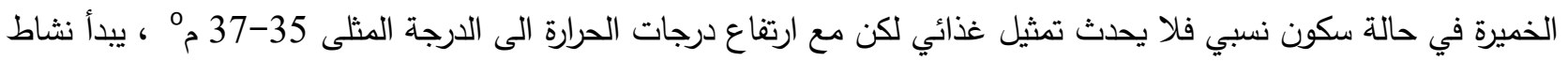
انزيمات التمثيل الغذائي على اثده، ان إرتفاع درجات الحرارة الى ما فوق 44 م تعمل على تغيير طبيعة السايتوبلازم ومايحتويه من بروتينات وانزيمات ، ترتبط سمة التحمل الحراري ارتباطا وثيقا ببنية غثاء الخلية وتحديدا محتوى الدهون فيها كما قد يخضع لتحكم العديد من الجينات ، وعلى الرغم من تحديد البعض منها الا ان الكثف عنها بالكامل لايزال قيد الدراسة [47] .تتقق هذه

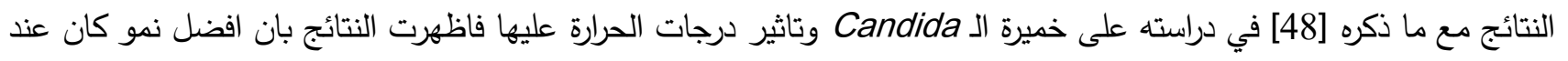

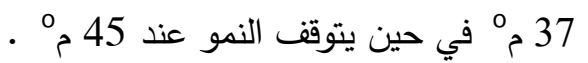


Journal of Education and Science (ISSN 1812-125X), Vol: 30, No: 3, 2021 (150-166)

Special Issue for Proceeding of $3^{\text {rd }}$ National (1 $1^{\text {st }}$ international conference of biology) (ICBSUM 2021) 5, 6 July

College of Education for Pure Science, University of Mosul, Mosul, Iraq.

Candida spp جدول (4).تاثير اختلاف درجات الحرارة على نمو

\begin{tabular}{|c|c|c|c|c|}
\hline oدرجة حرارة 45م & oدرجة حرارة 37م & oدرجة حرارة 28م & oدرجة حرارة 23م & العينات \\
\hline- & + & + & + & C1 \\
\hline . & + & + & + & $\mathrm{C} 2$ \\
\hline - & + & + & + & C3 \\
\hline - & + & + & + & $\mathrm{C} 4$ \\
\hline - & + & + & + & C5 \\
\hline+ & + & + & + & C6 \\
\hline- & + & + & + & C7 \\
\hline+ & + & + & + & $\mathrm{C} 8$ \\
\hline - & + & + & + & C9 \\
\hline - & + & + & + & C10 \\
\hline
\end{tabular}

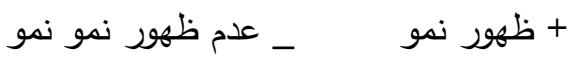

إككانية عزل خميرة Candida spp من مستشفيات الموصل من المرضى المصابين بداء المبيضات ـ ان الخميرة قيد الدراسة كانت

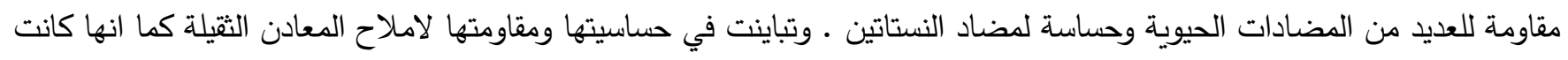
غير قادرة على تخمر سكر اللاكتوز بينما لها القدرة على تخمير عدد كبير من السكريات ـ وان هذه العزلات لها القدرة على النمو في مدى لهاي

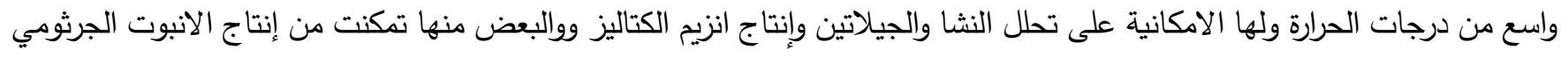
وكانت قادرة أيضا على انتاج السبورات الكلاميدية.

المصادر:

1- J. Z. Bresha "The yeast “ Arabic buplishing, King Saaud university .S A,2012. (in Arabic).

2- K. A. AL-Kafaji and Z. K. AL-Maamory "the most important medical fungi, Isolation, identification and treatment" Albasaer bublishing Lebnan Beirut,2013. (in Arabic).

3- C. Kurtzman, W. Fell, T. Boekhout and V. Robert "Methods for isolation, phenotypic characterization and maintenance of yeasts. In: The yeasts, a taxonomic study", 5th edn. Elsevier,Boston, pp 87110,2011 .

4- AL-Yasiry, A. M. Dental health of osteopenia diabetes mellitus male patients. Med. J. Babylon, 15(2), 118_123. 2018.

5- A.Al - Hussainy and M. Kadhim "Isolation and identification of dermatophytes fungi from under two year children in diaber location ",Al-Qadisiyah journal for pure science , Vol 19 No 3 pp 98-109,2014. 


\section{Journal of Education and Science (ISSN 1812-125X), Vol: 30, No: 3, 2021 (150-166) \\ Special Issue for Proceeding of $3^{\text {rd }}$ National (1 $1^{\text {st }}$ international conference of biology) (ICBSUM 2021) 5, 6 July College of Education for Pure Science, University of Mosul, Mosul, Iraq.}

6- J. Hannula "Clonal types of oral yeasts in relation to age health and geography". Academic Dissertation, Instituente of Dentistry Department of Periodontology, University of Helsinki, Finland. PP: 1 -57, 2000.

7- J.A. Cortes, P. Reyes, C. Gomez, G. Buitrago and A.L. Leal "Fungal bloodstream infections in tertiary care hospitals in Colombia”. Rev Iberoam Micol. ,28:74-8,2011.

8- F.L.Mayer, D. Wilson and B. Hube, "Candida albicans pathogenicity mechanisms Virulence"., 4(2), p.119_128. 2013

9- H.L. Cheah, V. Lim, and D. Sandai "Inhibitors of the glyoxylate cycle enzyme ICL1 in Candida albicans for potential use as antifungal agents". PloS one, 9(4). 2014.

10- J. A. Barnett "A history of research on yeasts 12 : medical yeasts part I, Candida albicans Yeast", $25: 385-417,2008$

11- B. J. Kullberg and M. C. Arendrup “Invasive candidiasis”'. N. Engl. J. Med. 373, 1445-1456 2015.

12- T. P. McCarty and P. G. Assae "Pappas, Invasive candidiasis". J. Infect. Dis. Clin. North Am. 30, $103-124,2016$.

13- L.Kunyeit, A., KA, and R. P. Rao," Application of Probiotic Yeasts on Candida Species Associated Infection", Journal of Fungi, 6(4), 189, 2020

14- C. Onyewu, and J. Heitman, "Unique applications of novel antifungal drug combinationns" AntiInfective Agents in Medical Chemistry , 6,3-15, 2007.

15- E.L. Hazen and R.Brown (1950). Science ,112,423.(Cited by Onyewu and Heitman ), 2007.

16- J. D. Sobel “Genital candidiasis” Medicine, 38(6): 286-290,2010 .

17- S. E. Brown, J. A.Schwartz, C. K. Robinson, D. E. O’Hanlon, L.Bradford and X .He. "The vaginal microbiota and behavioral factors associated with genital Candida albicans detection in reproductive-age women.Sex. Transm”.Dis. 46, 753-758. doi: 2019

18- J. YanoSobel, J. D., Nyirjesy, P., Sobel, R., Williams and V. L., Yu, Q., Current patient perspectives of vulvovaginal candidiasis: incidence, symptoms, management and post-treatment outcomes. BMC Womens Health 19:48. doi: 10.1186/s12905-019-0748-8, 2019.

19- A. Shukla, and J. D. Sobel "Vulvovaginitis caused by Candida species Following antibiotic exposure”Curr. Infect. Dis. Rep. 21:44. doi: 10.1007/s11908-019-0700-y. 2019

20- R. M,Atlas A. E. Brown and L.C.,Parks," Laboratory Manual Experimental Microbiology ."Mosby Year Book, Inc. 17(3) pp 283-289 (1995).

21- Y. Kourkoutas, S. Dimitropoulou, R.Marchant and I. M. Banat’Whey liquid waste of dairy industry as raw material for fermentation with the thermophilic Klyveromyces marxianusI'MB3. J. Environ. Sci. Tech; 7:226-233,2001.

22- Dar , N. Isolation and Characterization of Heavy Metals Resistant yeast from Industrial Effluents and their Use in Environmental Cleanup . ph. D. Thesis Punjab ,Univ.Lahore .Pakistan ,2004. 


\section{Journal of Education and Science (ISSN 1812-125X), Vol: 30, No: 3, 2021 (150-166) \\ Special Issue for Proceeding of $3^{\text {rd }}$ National (1 $1^{\text {st }}$ international conference of biology) (ICBSUM 2021) 5, 6 July College of Education for Pure Science, University of Mosul, Mosul, Iraq.}

23- Mac Faddin "Biochemical tests for Identification of Medical bacteria Macro - and micronutrient in alkaline soils" Commun Soil Sci. Plant Anal., Vol. 8 , p. 195-207 , 1980.

24- A. Neama "Biochemical tests used in the identification” College of education for pure sciences ,Diyala University (In Arabic), 2013.

25- S. Neji, I.Hadrich, H. Trabelsi, S. Abbes, F. Cheikhrouhou, H. Sellami and A. Ayadi”Virulence factors, antifungal susceptibility and molecular mechanisms of azole resistance among Candida parapsilosis complex isolates recovered from clinical specimens". Journal of biomedical science, 24(1), $1-16.2017$

26- B. E. Forbes, D.F. Sahm and A.S. Weissfeld.” Bailey and Scott's Diagnostic microbiology", 12th ed. Mosby Elsevier.,Texas, USA, 2007.

27- R.S. Gupta, R. Baral, B. Khanal and B. Gupta" Phenotypic Characterization of Clinical Isolates of Candida Species in Eastern Part of Nepal”. Res, J.Pharm, Biol. Chem, Sci.,7(2): pp.204-212, 2016.

28- D.R.Hospenthal , M.L.Beckius , K.L. Floyd , L.L. Horvath , and C.K.Murray ,. "Presumptive identification of Candida species other than C.albicans , C.krusei and C.tropicalis with the chromogenic medium CHROMagar candida" 3 (5) . pp:1-10,2006.

29- M. M. Belan Ali, S. M. Abdullah, and K. I. Othman "Isolation and Identification Candida spp from Urine and Antifungal "Susceptibility Test”. Ira. J. Sci., 59(4B), 1981-988,2018.

30- H. Abdulla, and E.A.Mustafa," Rapid Detection of Candida species Isolated from Denture Stomatitis Patients using Phenotypic methods and Chromogenic agar media" Al-Raf, Dent J.20(1), pp 125_133, 2020.

31- T.Wibawa, and A.T. Aman" Virulence of Candida albicans isolated from HIV infected and non infected individuals" SpringerPlus, 4(1), p.408,2015.

32- Y. Kourkoutas, S. Dimitropoulou, R.Marchant and I. M. Banat”Whey liquid waste of dairy industry as raw material for fermentation with the thermophilic Klyveromyces marxianusI'MB3. J. Environ. Sci. Tech; 7:226-233,2000.

33- S. A,Marinho, , A. B.,Teixeira, , O. S. Santos,R.F., Cazanova ,C.A.S,Ferreira., , K., \& Oliveira , , S. D. D. , Cherubini. "Identification of Candida spp. by phenotypic tests and PCR. Brazilian Journal of Microbiology”, 41(2), 286-294,2010.

34- S. Giri, and M. J. Kindo. "Evaluation of five phenotypic tests in the identification of candida species" Nat J Lab Med, 4, 13-18,2015.

35- G. N.B. Brito , A. C . Inocêncio S. M. R. Querido , A. O. C. Jorge and C. Y. Koga Ito “ In vitro antifungal susceptibility of Candida spp . oral isolates from HIV - positive patients and control individuals". Braz . Oral Res ., 25 ( 1 ) : 28-33 . 2010. 


\section{Journal of Education and Science (ISSN 1812-125X), Vol: 30, No: 3, 2021 (150-166) \\ Special Issue for Proceeding of $3^{\text {rd }}$ National (1 $1^{\text {st }}$ international conference of biology) (ICBSUM 2021) 5, 6 July College of Education for Pure Science, University of Mosul, Mosul, Iraq.}

36- F . Amran; M. N. Aziz, H. M . Ibrahim , N. H. Atiqah, S. Parameswari , M. R. Hafiza and M. Ifwat ." In vitro antifungal susceptibilities of Candida isolates from patients with invasive candidiasis in Kuala Lumpur Hospital”, Malaysia . J. Med . Microbiol ., 60 : 1312 - 1316 , 2011.

37- T. C. White, S . Holleman , L. F. Mirels and D. A. Stevens, "Resistance mechanisms in clinical isolates of Candida albicans “. Antimicrob ,Agents Chemother ., 46 ( 6 ) 1704-1713, 2002.

38- M. M., Kukde Basak, S., \& , D. S. SeloKar, Effect of Heavy Metal Ions on Candida Isolated from HIV Positive Patients. Journal of Clinical \& Diagnostic Research, 13(4),2019.

39- A. R. S. A., Al-Khafaji Gel electrophoresis. College of Science for girls, Babylon University Master thesis (In Arabic) (2016).

40- S. K. R.Oliveira, D. C. V.dos Anjos, , L. H. B. Gonçalves, T. A. F. Ferro, S. G. Monteiro, P. D. M. S. Figueiredo, and C. de Andrade Monteiro," PREVALÊNCIA E PRODUÇÃO DE ENZIMAS POR ISOLADOS DE Candida PROVENIENTES DE AMOSTRAS DE SECREÇÃO VAGINAL, Revista de Patologia Tropical"/Journal of Tropical Pathology, 42(2). 2013.

41- A. Aruna, M. Nagavalli, V. Girijashankar, S. P. D., Ponamgi, V. Swathisree and L. Venkateswar Rao, "Direct bioethanol production by amylolytic yeast $\mathrm{C}$ andida albicans", Letters in applied microbiology, 60(3), 229-236, 2015.

42- S. Neji, I.Hadrich, H. Trabelsi, S. Abbes, F. Cheikhrouhou, H. Sellami and A. Ayadi'Virulence factors, antifungal susceptibility and molecular mechanisms of azole resistance among Candida parapsilosis complex isolates recovered from clinical specimens". Journal of biomedical science, 24(1), $1-16,2017$.

43- T. Matare, P. Nziramasanga, L. Gwanzura and V. Robertson, " Experimental germ tube induction in Candida albicans: An evaluation of the effect of sodium bicarbonate on morphogenesis and comparison with pooled human serum”. BioMed Res. Inter, 2017.

44- B. Böttcher, C. Pöllath, P. Staib, B. Hube and S. Brunke "Candida species rewired hyphae developmental programs for chlamydospore formation”. Fro. Microbiolo., 7 ,17, 2016.

45- N. M. S. Abdulkhaleq"Prevalence of staphylococcus species and candida species in pregnant and nonpregnant women in genital tract with detection of norA and sdrM genes",University of Diyala,Collage of Science, 2020.

46-C. Pataro, A. Santos, S. R.Correa, P. B. Morais; V. R. Linardi and C.A . Rosa”Rev. Microbiol".,29: 104-108,1998.

47- S. G. Nadeem, A. Shafiq, S. T. Hakim, Y. Anjum, and S. U. Kazm " Effect of growth media, pH and temperature on yeast to hyphal transition in Candida albicans.open journal of medical microbiology ,vol.3,no.3, 2013 .

48- F. C. Odds, " Effects of temperature on anti-Candida activities of antifungal antibiotics ". Antimicrobial agents and chemotherapy, 37(4), 685-691 (1993). 